\title{
The effects of hypnosis and symptom interpretation on jurors' perceptions of recovered memories of child sexual abuse
}

\author{
Sarah Nunley
}

Follow this and additional works at: https://researchrepository.wvu.edu/etd

\section{Recommended Citation}

Nunley, Sarah, "The effects of hypnosis and symptom interpretation on jurors' perceptions of recovered memories of child sexual abuse" (2014). Graduate Theses, Dissertations, and Problem Reports. 6333. https://researchrepository.wvu.edu/etd/6333

This Thesis is protected by copyright and/or related rights. It has been brought to you by the The Research Repository @ WVU with permission from the rights-holder(s). You are free to use this Thesis in any way that is permitted by the copyright and related rights legislation that applies to your use. For other uses you must obtain permission from the rights-holder(s) directly, unless additional rights are indicated by a Creative Commons license in the record and/ or on the work itself. This Thesis has been accepted for inclusion in WVU Graduate Theses, Dissertations, and Problem Reports collection by an authorized administrator of The Research Repository @ WVU. For more information, please contact researchrepository@mail.wvu.edu. 
The effects of hypnosis and symptom interpretation on jurors' perceptions of recovered memories of child sexual abuse

Sarah Nunley, B.S.

\author{
Thesis submitted to the \\ Eberly College of Arts and Sciences \\ at West Virginia University \\ in partial fulfillment of the requirements \\ for the degree of \\ Master of Science \\ in \\ Psychology
}

Elisa Krackow, Ph.D., Chair

Steven Kinsey, Ph.D.

Constance Toffle, Ph.D.

Department of Psychology

Morgantown, West Virginia 2014

Keywords: jurors' perceptions; recovered memories; hypnosis; psychological symptoms; child sexual abuse

Copyright Sarah Nunley 2014 


\begin{abstract}
The effects of hypnosis and symptom interpretation on jurors' perceptions of recovered memories of child sexual abuse
\end{abstract}

\title{
Sarah Nunley, B.S.
}

The current study examined mock jurors' perceptions of recovered memories of child sexual abuse. Participants were presented with one of four written vignettes of an adult female who recovers memories of child sexual abuse during therapy. Two variables in the vignettes were manipulated: the method of memory recovery (hypnosis informed vs. control uninformed) and presentation of psychological symptoms commonly related to history of sexual maltreatment (symptoms informed vs. symptoms uninformed). Participant mock jurors were asked to respond to questions regarding credibility, defendant guilt, and award of monetary damages. The continuous dependent variable analyses found significant results with regard to plaintiff credibility and defendant guilt with the hypnosis uninformed condition. Additionally, the hypnosis uninformed condition of the dichotomous dependent variable analyses significantly predicted the likelihood of participants deciding the defendant guilty, as well as the plaintiff as credible. Based on these findings, mock jurors' perceived hypnosis to be detrimental to memory recovery. 
Table of Contents

I. Introduction
a. Hypnosis and Memory
b. Jurors' Perceptions of Eyewitness Memory
c. Juror's Perceptions of Recovered Memories
9
d. Psychological Symptoms Associated with Child Sexual Abuse

II. Current Study

a. Hypotheses and Research Questions

III. Method
a. Participants
16
b. Materials and Procedure

IV. Results
a. Data Analyses

V. Discussion

VI. Tables and Figures

VII. References 
The effects of hypnosis and symptom interpretation on jurors' perceptions of recovered memories of child sexual abuse

Repressed memories of child sexual abuse have been commonly reported in the literature, but the question of their veracity has been hotly debated (Pezdek \& Banks, 1996). In a landmark paper, Loftus (1993) reported data demonstrating that false memories of stressful childhood events can be implanted by means of suggestion. Participants reported highly detailed narratives of false events in which they had high levels of confidence. Since then, numerous researchers have replicated and extended these findings. Research also demonstrates that the majority of repressed memories are created in the context of therapy, by means of problematic memory recovery techniques (see Lynn, Lock, Loftus, Krackow, \& Lilienfeld, 2014, for a review). One of the most common therapeutic methods used to recover memories in therapy is hypnosis (Lynn et al., 2003), with the first documented use of hypnosis in the court occurring around the year 1897 (Lynn, Neuschatz, and Fite, 2001).

However, hypnosis creates inaccurate memories, including memories of highly implausible events such as UFO abductions and increases in confidence in these false memories (see Lynn, Lock, Myers, and Payne, 1997, for a review). At the same time, the myth that hypnosis can be used to recover accurate memories prevails among the general public and among clinicians (Johnson \& Hauck, 1999, Poole, Lindsay, Memon, and Bull, 1995). Despite research findings, clinicians continue to use hypnosis as a memory recovery technique (Ost, Wright, Easton, Hope, \& French, 2013). Given that alleged victims of child sexual abuse have the option to take legal action against their alleged perpetrators even years after the alleged wrongdoing, numerous cases involving repressed memories have gone to court. One important question is how jurors perceive repressed memories created by hypnosis. The study herein will 
address this question. It is also the case that people who seek psychotherapy services do so because they are experiencing psychological symptoms that cause distress or impair their functioning (DSM-IV-TR, APA, 2004). Clinicians have long believed that sexual abuse causes psychopathology. In fact, memory recovery therapists often view psychological symptoms as indicators of sexual abuse and then seek to recover abuse-specific memories as a method of healing their client (Loftus, 1993). Therefore, people who present in court with recovered memories also typically present in court with psychological symptoms. The question remains as to whether these symptoms add to jurors' perceptions of the credibility of repressed memories.

The current study explored this question using a design in which mock jurors received a description of an adult female who reports a repressed memory under one of four varying conditions: The memory was elicited by hypnosis and the plaintiff was in therapy for psychological symptoms that could be viewed as having resulted from sexual abuse (Condition 1: hypnosis informed, symptoms informed). This was contrasted with three other conditions: Condition 2: hypnosis informed, symptoms uninformed; Condition 3: control uninformed, symptoms informed, and Condition 4: control uninformed, symptoms uninformed. Mock jurors' ratings of the plaintiff's credibility, willingness to award monetary damages, and the defendant's guilt were obtained. However, before presenting the methodological details and results, a review of the literature on jurors' perceptions of repressed memories, jurors' perceptions of child sexual abuse, hypnosis and memory veracity, and the relation of psychological symptoms to adult survivors of child sexual abuse will be reviewed.

\section{Hypnosis and Memory}


Despite popular belief by researchers, clinicians, and the public that hypnosis may be used to enhance or recover memories, empirical data from numerous studies has found that hypnosis produces false (implausible) memories and therefore should not be used for memory enhancement. With respect to false/implausible memories, the assumption is that memory reports below the age of 24 months are false given that 24 months is considered to be the cut-off for infantile amnesia (Lynn et al., 2003) and that unconfirmable events such as UFO abductions represent false memories. More specifically, Malinoski and Lynn (1999) asked the question of whether hypnosis could create improbable memories below the infantile amnesia age cut-off of 2 years of age. In the first session, multiple individual difference measures that were hypothesized to be related to the production of false memories, including hypnotizability, were administered. One week later, the participants were asked to report their earliest autobiographical memories. Age of the memory and a rating of perceived confidence in accuracy were also obtained. If the participant declined reporting any early memories, they received procedures to enhance the production of early memories. More specifically, the interviewer asked the participants to close their eyes and "get in touch" with memories from long ago. The participants were purposefully misinformed that research had shown that everyone could retrieve memories of early events if they just tried hard to focus and concentrate. The interviewer continually asked the participants to focus on even earlier memories and report them until the participants denied that they could recall further memories. Malinoksi and Lynn (1999) found that 78\% of participants reported memories at or below the infantile amnesia age of 2 . Highly hypnotizable participants were more susceptible to producing early implausible childhood memories. Overall, the participants had high degrees of confidence in their earliest memory reports. Further, participants reported 
they did not feel much pressure to report early memories rendering it unlikely that demand characteristics account for the production of these false memories.

In another study, Nash, Johnson, and Tipton (1979) investigated the differences in the production of false memories between hypnotically age-regressed subjects and controls instructed to fake hypnosis. Participants in their study were separated into two groups; the first group was made up of hypnotically age-regressed participants, while the second group was asked to fake hypnotic age regression. In the hypnotized group, participants were hypnotically age regressed back to the age of 3 . Under hypnosis, they were asked to identify a translational object(s) sought in stressful situations from their early years, such as a baby blanket or a teddy bear. They were then asked for several ratings to identify whether this named object really functioned as a translational object (e.g., desired at times of stress, elicited emotional attachment). Significantly more hypnotically regressed participants spontaneously identified a translational object, identified using this object as a translational object, and displayed the expected attachment to the object. To rule out the explanation that more people in the hypnotic group might have actually reported real transitional objects from their childhood, these data were compared to a random sample of young children and the above reported rates in the hypnotic group were significantly higher. This study is important to the present study due to the production of false memories of translational objects in hypnotically regressed participants.

In another study examining whether hypnosis can elicit false memories below the infantile amnesia age cut-off, Marmelstein and Lynn (1999) provided half of the participants with expectancies that they could recall memories from the first week of life, while the remainder of the participants were provided with no specific expectancies regarding the age of earliest memories. All participants were hypnotized. Participants were questioned about their 
earliest memory before and after hypnosis. Nearly $2 / 3$ of participants who reported memories below the age of 24 months, regardless of whether they were provided with expectancies, emerged after participants were hypnotized.

In another study, Lynn and Pezzo (1994) conducted an experiment involving an improbable event and hypnosis (i.e., UFO encounters). Participants were told that the hypnotist would hypnotize them and have them recall a bizarre event that involved driving in the country and them leaving the car to witness mysterious moving lights in the sky. Afterward, they were told they would have no clear recall of being in the car as well as not noticing that there were two hours of missing time that they could not account for. After being given this information, participants were hypnotized and age regressed to the time they were in the field, and then asked to describe everything they could see, feel, and hear. Afterward, a structured interview was administered that began with open-ended questions, but got increasingly more specific as it went on. Once these procedures were completed, participants filled out a questionnaire that included questions dealing with participants' belief in UFOs, memory gaps in terms of recollection of the sighting, as well as whether they had sighted what they believed to be a UFO. Almost $50 \%$ of participants reported UFO consistent experiences including interacting with aliens and boarding a UFO spacecraft. This outcome adds to the building research base that shows how hypnosis can produce false memories even for implausible events.

Previous researchers have criticized the above work due to the fact that memories being studied were not memories of emotional events. The following study conducted by Krackow, Lynn, and Payne (2006) was the first study to examine the impact of hypnosis on emotional memories of Princess Diana's death. Within 72 hours of Princess Diana's death, undergraduates completed a questionnaire that required them to write a narrative about when they first learned 
the news of the death as well as respond to specific questions. A portion of participants returned to the lab 11-12 weeks after learning the news of Princess Diana's death. In the second session, participants were divided into three separate memory enhancement technique conditions, one being hypnosis. These participants were then reminded about the questionnaire that was completed earlier and that the hypnosis would "enhance your memory of the circumstances surrounding the Princess' death." When the open-ended memory reports were examined, Krackow and colleagues (2006) found that hypnotized participants retained less of the detail provided in their original narratives in comparison to other memory enhancement conditions therefore providing additional evidence that hypnosis can be detrimental to recall (Krackow, Lynn, \& Payne, 2006). When only flashbulb memory components were abstracted from the narratives, the data showed that hypnotized participants omitted significantly more flashbulb memory components than participants in the other two memory enhancement conditions. Moreover, even warning people prior to the hypnotic induction that hypnosis can create false memories does not reduce false memories (Green, Lynn, and Malinoski, 1998).

Therefore, in summary, the current literature shows that hypnosis increases the production of false or inconsistent memories including memories below the infantile amnesia line, memories of implausible events, and emotional memories.

\section{Jurors' Perceptions of Eyewitness Testimony}

Not only is it important that memory recovery techniques are examined for their impact on the quantity and quality of memories, but it is also important how memory recovery techniques are perceived by courtroom personnel including jurors. Before reviewing the findings from studies on jurors' perceptions of repressed memories, findings from other studies on jurors' 
perceptions of eyewitness testimony will be reviewed. A variety of factors, including age, level of involvement in the event, use of expert testimony, courtroom questioning style, and knowledge of the child sexual abuse literature influence jurors' perceptions of the credibility of eyewitnesses and likelihood to convict a defendant. In the first study conducted on jurors' perceptions of child witnesses, Goodman and colleagues (1987) found that the credibility of the eyewitness increased with age. Adults were viewed as more credible than an older and younger group of children, but ratings of defendant guilt did not show age differences (Goodman, Golding, Helgeson, Haith, \& Michelli, 1987). However, other studies find that younger children are viewed as more credible than older children. For example, Goodman and colleagues (2002) examined perceptions of older and younger memory reports of abuse following a 4-year delay. That is, 4 years earlier, children participated in a research study in which no abuse or genital touch occurred. Children simply played with a research assistant and were interviewed with suggestive questioning potentially relevant to a child abuse investigation following the play event. Professionals were shown videotapes of the children providing their memory during the interviews. Prior to viewing the videos, professionals were misled to believe that the interviews were from active sexual abuse investigations. Although statistical analyses of children's memory reports provided during the study showed few significant age differences in memory accuracy between 7 and 10 year olds, professionals were more likely to believe that a 7 -year-old was abused in comparison to a 10-year-old child thereby highlighting the credibility of younger children (Goodman, Batterman-Faunce, Schaaf, \& Kenney, 2002). Still yet, other studies show that preschool children can be viewed as more credible than older children and adults (Bottoms \& Goodman, 1994; Holcomb and Jacquin, 2007). Regardless of the findings in the jurors' perceptions literature, the memory literature shows that both children and adults can be both 
accurate informants and inaccurate informants depending on numerous determinants (Holliday, Brainerd, \& Reyna, 2011; Krackow \& Lynn, 2003; Krackow \& Lynn, 2010).

Research has found that age of a child can affect jurors' perceptions, but other factors such as level of involvement in an event have been shown to influence juror's perceptions. Holcomb and Jacquin (2007) designed a study to examine the effects of the combination of child eyewitness age and the level of involvement (e.g., victim of sexual maltreatment vs. bystander to sexual maltreatment) on juror's perceptions and verdicts in a sexual abuse trial. Jurors were presented with case summaries that varied with respect to the age of the child eyewitness as well as the level of involvement in alleged sexual abuse. Results demonstrated that bystanders were more likely to elicit defendant guilty ratings than victims.

Additionally, research has also examined credibility of adult eyewitnesses at various ages across the lifespan. These data have shown that jurors viewed younger, middle-aged, and older adults as equally reliable witnesses despite the fact that older adults provided less accurate memory reports (Brimacombe, Quinton, Nance, \& Garrioch, 1997).

Another way in which jurors' perceptions may be influenced is through the use of expert or non-expert testimony. Two investigations presented trial information that included or did not include an expert witness (Pezdek, Avila-Mora, \& Sperry, 2010; Woody and Forrest, 2009). In both investigations, jurors gave fewer guilty verdicts when an expert witness provided testimony. This finding held true regardless of the presentation style of the expert witness (Pezdek, AvilaMora, \& Sperry, 2010).

Courtroom questioning style has also shown to have influence on jurors' perceptions of eyewitness accuracy. In a study conducted by Wheatcroft, Wagstaff, and Kebbell (2004), the 
effects of different questioning styles on inferences made by jurors hearing the questioning with regard to accuracy and confidence of the witness being questioned was researched. Participants in this study were randomly assigned to one of three questioning style conditions: control, lawyerese (e.g., To the best of your knowledge, did x happen?), and lawyerese with negative feedback. In this last condition, the attorney expressed doubt about the participant's response each time the person responded "no" regardless of whether "no" was the correct answer. Each participant was told that he or she would be listening to two audio recordings of two separate witnesses being interviewed. After listening to both audio recordings, participants were to fill out a questionnaire with three specific questions: (1) How accurate do you think the witness was? (2) How confident do you think the witness was? (3) How fair do you think the questioning was? In general, the trend was for participants to rate the witnesses in the lawyerese with negative feedback condition to be the least accurate, and those questioned with lawyerese to be the most accurate. Wheatcroft and colleagues (2004) found that jurors perceive confident witnesses as accurate.

Finally, knowledge of the child sexual abuse literature influenced jurors' perceptions of child sexual abuse cases. If mock jurors had less knowledge of the literature, they were less likely to find the child credible in these cases (Goodman-Delahunty, Cossins, and O'Brien, 2010).

\section{Jurors' Perceptions of Recovered Memories}

An important question regarding recovered memories that are typically recovered during therapy by the use of memory recovery techniques, including hypnosis, is whether or not the public actually believes in their veracity. Recovered memories are hotly debated in the 
literature (Pezdek \& Banks, 1996). Less than a handful of studies have examined whether mock jurors view recovered memories as being credible. The literature about to be reviewed below shows that mock jurors are likely to believe repressed memories of child sexual abuse at the same level as continuous memories of child sexual abuse.

Specifically, Golding and colleagues (1995) investigated the believability of repressed memories compared to nonrepressed continuous memories of childhood maltreatment. They also varied whether courtroom testimony was provided after a long or short delay. Participants were presented with a summary of a child sexual assault trial. After reading this summary, participants were to complete questions about alleged victim's credibility. Those who were given a summary of repressed memories of a child sexual assault with courtroom testimony provided after a short delay were more likely to find the witness more believable (Golding, Sego, Sanchez, \& Hasemann, 1995). In a second investigation, Golding, Sego, and Sanchez (1999) conducted a study in which the effect of multiple childhood sexual assaults versus a single assault on the believability of the following memory types: immediately reported child sexual abuse; adult continuous memories of child sexual abuse; and repressed memory of child sexual abuse were assessed by mock jurors. Taken together, findings showed that mock jurors believed the alleged victim who testified about a repressed memory and the alleged victim who, as an adult reported a continuous memory of childhood sexual abuse, less than a child victim who reported her maltreatment within a year of its occurrence. These findings suggest that there were no significant differences between when adults testify regarding repressed or continuous memories of child sexual abuse. Interestingly, the greater the number of assaults someone reported led to a marginally significant $(p=.059)$ higher victim believability across all conditions. 
Coleman, Stevens, and Reeder (2001) examined the believability of recovered memories uncovered by hypnosis compared to those that were suggested by the therapist or discovered in the course of therapy. In their first study, plaintiffs who had repressed memories uncovered by hypnosis were found to be more credible. In addition, hypnosis led to more guilty verdicts. In the second study completed by Coleman, Stevens, and Reeder, they examined jurors' perceptions of lawsuits against therapists who used hypnosis to recover memories. In this study, the flip side was also true. Hypnosis was viewed as a harmful technique with regard to creating memories. Jurors also found therapists who used hypnosis to be less competent and more responsible for having caused harm to their clients and were more likely to convict these therapists.

\section{Psychological Symptoms Associated with Child Sexual Abuse}

Typically during cases of memory recovery therapists ascertain whether child sexual abuse has occurred based on a client's current psychological symptoms (Mazzoni, Loftus, \& Kirsch, 2001). The current study investigates whether jurors' perceptions of psychological symptoms associated with child sexual abuse (see Rind, Tromovitch, \& Bauserman, 1998 for contrasting views) increase or decrease the credibility of the prosecuting witness, given that no previous studies have asked this research question. Childhood sexual abuse is associated with a multitude of psychological symptoms, such as depression, anxiety, self-injurious behaviors, eating pathologies, relationship problems, dissociation, and somatic symptoms. Maniglio (2010) found after conducting four meta-analytic reviews that there is evidence that across methodologies, samples, and measures, survivors of child sexual abuse are significantly at risk for depression. 
Childhood anxiety symptoms and anxiety disorders have been identified as short- and long-term psychological correlates of child sexual abuse. Results from a study conducted by Chaffin, Silovsky, and Vaughn (2005) support the idea that the experience of child sexual abuse has a direct link with the development of childhood anxiety disorders. Further, an increased risk for the onset of childhood anxiety disorders was most clearly associated with the onset and experiencing of child sexual abuse. The rates of two specific childhood anxiety disorders, separation anxiety and phobias, increased four times with the onset of child sexual abuse. Interestingly, very specific elements of child sexual abuse, such as force, violence, or coercion, connected with the child sexual abuse, as well as pressure to keep the abuse secret, were associated with developing posttraumatic stress disorder.

A connection between child sexual abuse and self-injurious behaviors has also been found in the literature. For example, incest is often present in the history of self-mutilators (Turell \& Armsworth, 2003). Self-mutilation, typically in the form of cutting or burning oneself, occurred in a child sexual abuse survivor when one of the following variables was present: physical and physiological abuse in one's family of origin, history of anorexia/bulima, current severe dissociation or depression (Turell \& Armsworth, 2003).

Not only is it possible for survivors of child sexual abuse to have depression, anxiety, or partake in self-mutilation, they may also have an eating disorder. Findings from Messman-Moore and Garrigus (2007) suggest that symptoms of eating disorders are more likely to occur and have greater severity among individuals reporting histories of childhood abuse and that these symptoms are related to both childhood physical and emotional abuse. Claes and Vandereycken (2007) found that within half of their patient sample, sexual abuse was reported and it was significantly associated with the eating disorder diagnostic subtype of bulimia nervosa. 
Another area of functioning found to relate to history of child sexual abuse is difficulty in interpersonal relationships. Runstein-McKean and Huntley (2001) reviewed more than 20 studies in which child sexual abuse survivors report a host of problems in romantic and nonromantic close relationships including but not limited to the following: higher rates of remaining single; feelings of distrust, particularly of men; lower satisfaction in opposite sex relationships; feeling less connected to people in general; sexual dysfunction; and divorce. Related to difficulties in interpersonal relationships, child sexual abuse survivors are more likely to have insecure attachments than their nonmaltreated counterparts (Rumstein-McKean \& Huntley, 2001).

Dissociation is one of the most frequently diagnosed pathologies associated with child sexual abuse. Dissociation, defined as involuntary avoidance of traumatic stimuli, has also been found to play a mediating role between sexual abuse and a variety of mental health outcomes (Lynn \& Rhue, 1994; Kisiel \& Lyons, 2001). Additionally, Farley and Keaney (2008) found both somatization and dissociation highly correlated in subjects with a history of child sexual abuse.

Somatic symptoms specifically represent physical complaints that can encompass a range of severity. Exposure to trauma has been associated with increased rates of somatic symptoms, such as headaches, stomachaches, and muscle tension. These somatic symptoms may cause interference in daily functioning and may also affect academic, emotional, and social well-being due to impairment in memory and decreased sleep.

In sum, according to some literature, people with histories of sexual abuse can present with a variety of psychological symptoms. However, according to a large meta-analysis of studies examining the link between child sexual abuse and psychopathology (Rind et al., 1998), 
sexual abuse does not cause psychopathology, despite data from individual studies and widespread beliefs to this effect among clinicians. That is, adults with a history of sexual abuse are no more likely to experience any DSM-IV pathology than adults without a history of sexual abuse.

However, memory recovery therapists often use current psychological symptoms to "determine" that their client was maltreated. Upon using symptom interpretation, the memory recovery therapists then employ memory recovery techniques such as hypnosis to recover memories of child sexual abuse. Given that hypnosis is successful in recovering false as opposed to accurate memories, these recovered memories risk being inaccurate but confidently believed by the individual (Golding, Sego, Sanchez, \& Hasemann, 1995). There have been numerous court cases of recovered memories created in psychotherapy (Coleman, Stevens, \& Reeder, 2001; Lynn, Fassler, \& Knox, 2005). However, no research to date has examined how jurors' perceive the combination of a publically credible memory enhancement technique plus the combination of common psychological symptoms in the creation of repressed memories. Therefore, the current study employed a 2 (hypnosis vs. undisclosed memory recovery method control) X 2 (psychological symptoms vs. symptoms undisclosed control) design to determine whether these variables impact jurors' perceptions of repressed memories.

More specifically, mock jurors were presented with one of 4 written vignettes of a fictional adult female who recovers memories of child sexual abuse in which the therapeutic technique (i.e., hypnosis) used to recover the memory is disclosed in the vignette or not disclosed and in which the psychological symptoms that brought the client into therapy are present or absent. Following reading the vignette, mock jurors responded to questions in which they were 
asked to rate the credibility of the plaintiff, the likelihood of defendant guilt, and amount of monetary damages awarded to the plaintiff.

\section{Hypotheses and Research Questions}

Hypotheses 1, 2, 3, and 4: There will be a main effect of hypnosis such when hypnosis is disclosed as the memory recovery technique, the plaintiff will be viewed as more credible and will be more likely to be awarded damages. The defendant will be rated as more guilty. It is expected that hypnosis will yield more credible ratings as opposed to not credible ratings, more ratings of defendant guilt as opposed to not guilty, and award monetary damages vs. do not award monetary damages in the logistic regression analysis.

Research questions 1, 2, 3, and 4: Will there be a main effect of disclosure of psychological symptoms? It is possible that mock jurors may view individuals with psychological symptoms as more credible, and therefore would be more likely to award monetary damages, and find the defendant guilty, but given that there is no research to date examining this issue, no hypotheses will be made. On the other hand, given the societal stigma of mental health problems, it is possible that people who present with mental health symptoms will be viewed as less credible, which may also translate into lower ratings of defendant guilt. This remains a research question for the credible vs. not credible, defendant guilty vs. not guilty, and award monetary damages vs. do not award monetary damages outcomes measures in logistic regression analyses.

Research question 5: Will there be an interaction between hypnosis and psychological symptoms? It is possible that the combination of hypnosis and psychological symptoms will lead to perceptions of elevated credibility, defendant guilt, and award of monetary damages. 
However, given the lack of research on these topics, this will remain a research question. Logistic regression analyses can also be used to examine interactions with the dichotomous variables of credible vs. not credible, defendant guilty vs. not guilty, and award vs. do not award monetary damages. This too remains a research question.

\section{Method}

\section{Participants}

Participants were recruited from a national sample using an only survey Amazon Turk, an online portal system, with a link to Survey Monkey. Individuals were allowed to participate if they were between the ages of 18-years-old to 70-years-old and were U.S. citizens. Only data from U.S. citizens were included as in order to be a United States juror, one must have U.S. citizenship. Participants received $\$ 0.90$ following completion of the study. Data from a total of 211 participants were collected. Data from 44 (20.85\%) participants were excluded for the following reasons: $26(12.32 \%)$ due to incorrect answers on the comprehension items and 18 $(8.53 \%)$ due to failure to respond to survey questions, leaving a total of 167 participants for the current study with participants divided between the following conditions: Hypnosis and symptoms informed $(n=39$, males $=23$, females $=16)$, control uninformed and symptoms uninformed $(n=40$, males $=21$, females $=23)$, control uninformed and symptoms informed $(n=$ 44 , males $=17$, females $=27)$, and hypnosis informed and symptoms uninformed $(n=44$, males $=20$, females $=20)$ conditions. Eighty-six participants $(51.5 \%)$ self-identified as female and eighty-one participants (48.5\%) self-identified as male. One-hundred and thirty-three participants (79.6\%) self-identified as Caucasian, fourteen (8.4\%) as African American, seven (4.2\%) as Asian, ten $(6.0 \%)$ as Hispanic/Latino, one $(0.60 \%)$ as Biracial, one $(0.60 \%)$ as American Indian, 
and one $(0.60 \%)$ self-identified as another ethnicity not listed above. The overall mean age was 35.9 with an age range of 18 - to 68 -years-old $(S D=12.35)$.

\section{Materials and Procedure}

Data were collected using an online survey using Amazon Turk, an online portal system, with a link to Survey Monkey that contained the study materials. Participants were free to access the survey during time periods in late July and August 2014. Survey Monkey allowed for confidential participation, vignette randomization, and simple separation of participants into different groups in a random fashion.

After reading the consenting online form, participants were randomly assigned to one of four experimental conditions. In the study introduction, participants were told that they were to act as if they were a juror in the case they were about to read. They received one of 4 randomized vignettes. All vignettes included the same basic contextual information describing the case of a middle-aged adult female who recovers memories of recurrent sexual maltreatment between the ages of 4 and 7 by her father when her mother was away on business trips. Vignettes differed on the information provided regarding whether a memory recovery technique was used to gain information from the middle-aged female and whether the woman presents with psychological symptoms or not. Each vignette included brief contextual information about the child sexual assault allegation as well as a description of the method by which this information was obtained (hypnosis informed versus control uniformed). Two vignettes also included brief contextual information about child sexual abuse symptoms the woman presents with (i.e., anxiety, depression, binge eating, difficulty getting close to people). Vignettes are provided in Appendix 1. Vignette 1 described no memory recovery technique and no psychological symptoms present 
(hypnosis uninformed, symptoms uninformed). Vignette 2 described hypnosis as the memory recovery technique, with no psychological symptoms present (hypnosis informed, symptoms uninformed). Vignette 3 described no memory recovery technique used and psychological symptoms present (hypnosis uninformed, symptoms informed). Finally, vignette 4 included both the disclosure of hypnosis and psychological symptoms present (hypnosis informed, symptoms informed).

Participants then answered three comprehension questions to be certain that they had read and comprehended the information included in the vignettes. The comprehension questions included three general items regarding the event the woman recovered memories of, the identity of the alleged perpetrator, and the age the female was when the abuse occurred. Participants who were unable to respond accurately to at least two out of three questions did not have their data included in the analyses.

Participants then answered 9 total questions in the following order regarding witness credibility, defendant guilt, and likelihood of awarding monetary damages to the prosecuting witness, which were also used in Tessier and Krackow (2013), Bottoms and Goodman (1994), and Coleman, Stevens, and Reeder (2001).

Credibility. Participants rated the prosecuting witness on a scale from 1 (not at all credible) to 10 (there is no doubt in my mind that this woman is credible). Participants also assessed similar constructs of "believability" and "trustworthiness" in the same manner. An additional dichotomous item asked participants to decide whether the woman was credible or not credible. 
Guilt. Participants were asked to rate the guilt of the defendant on a scale of 1 (not at all guilty) to 10 (there is no doubt in my mind that the defendant is guilty). A similar question assessed defendant jurors' beliefs about whether the defendant committed the act in question. An additional dichotomous item asked participants to decide whether the defendant was guilty or innocent.

Award of Monetary Damages. Participants were asked to rate how many monetary damages they would award the prosecuting witness on a scale of $10 \%$ (would award $10 \%$ monetary damages) to $100 \%$ (would award $100 \%$ monetary damages). An additional dichotomous item asked participants to decide whether they would award monetary damages (yes) or not award monetary damages (no).

Two questions regarding participant familiarity with repressed/recovered memories followed. Participants were then presented with demographic questions that inquired about age, sex, and citizenship.

Question scoring. A total credibility score was computed by summing the Likert-type scale responses to the three credibility questions. A similar total defendant guilt score was computed by summing the Likert-type scale responses to the two defendant guilt questions.

\section{Results}

\section{Data Analyses}

Before beginning data analysis, alpha coefficients $(\alpha)$ were run to assess similarity in items assessing the prosecuting witness's credibility and defendant guilt. For the credibility items 
(sum of credibility, trustworthy, and believability), a strong correlation existed, $\alpha=0.96$. For the defendant guilt items (rating of guilt and belief of guilt), a strong correlation was found, $\alpha=0.92$.

\section{Continuous Dependent Variable Analyses}

Three separate 2 (hypnosis vs. no memory recovery method disclosed) by 2 (sexual abuse symptoms: present vs. undisclosed) analyses of variance (ANOVA) were conducted to investigate the effects of memory recovery technique and psychological symptoms on the following dependent variables: (1) total prosecuting witness credibility composite score composed of the sum rating of the credibility, trustworthiness, and believability questions, (2) total defendant guilt composite composed of the sum ratings of defendant guilt and belief in defendant guilt, and (3) the likelihood of mock jurors to award the plaintiff monetary damages with the use of Likert-type scale rating. Means and standard deviations are shown in Table 1 and Figures 1-3.

\section{Plaintiff Credibility}

A significant main effect was found with regard to hypnosis condition, $F(1,164)=4.82$, $p=.03, \eta^{2}=.03$, on the plaintiff credibility rating. This main effect indicates that the mean plaintiff credibility composite score was significantly greater for the control uninformed condition $(M=18.84, S E=.67)$ than for the hypnosis informed condition $(M=16.75, S E=.68)$. No significant main effect was found for the psychological symptom condition, $F(1,164)=1.61$,

$p=.21, \eta^{2}=.01$. Interaction effects were also non-significant, $F(1,164)=.68, p=.41, \eta^{2}=.00$.

\section{Defendant Guilt}


A significant main effect was found with regard to hypnosis condition, $F(1,164)=4.12$, $p=.04, \eta^{2}=.03$, on the defendant guilt rating. This main effect indicates that the mean defendant guilt composite score was significantly greater for the control uninformed condition $(M=11.92, S E=.54)$ than for the hypnosis informed condition $(M=10.37, S E=.54)$. No significant main effect was found for the psychological symptom condition, $F(1,164)=3.37, p=$ $.07, \eta^{2}=.02$. The interaction was also non-significant, $F(1,164)=.01, p=.94, \eta^{2}=.00$.

\section{Likelihood to Award Monetary Damages}

There were no significant main effects with regard to hypnosis condition $F(1,164)=.25$, $p=.62, \eta^{2}=.00$, or symptom condition $F(1,164)=.02, p=.89, \eta^{2}=.00$. The interaction was also non-significant $\left(F=1.66, p=.20, \eta^{2}=.01\right)$.

\section{Dichotomous Dependent Variable Analyses}

Three separate logistic regression analyses were conducted to predict dichotomous plaintiff credibility ratings (yes vs. no), defendant guilt ratings (yes vs. no), and likelihood of awarding monetary damages (yes vs. no). With regard to plaintiff credibility, the overall test of the model showed that hypnosis was a significant predictor of plaintiff credibility, $p=.010$, with an odds ratio of 6.73 , in which participants were more likely to indicate the plaintiff was credible opposed to not credible in the control uninformed condition (control uninformed conditions $=63$ credible vs. 21 not credible; hypnosis informed conditions $=47$ credible vs. 37 not credible). On the other hand, neither psychological symptoms nor the interaction were significant predictors of plaintiff credibility with $p$-values ranging from .25 to .72 and odds ratios as indicated by the Wald coefficients .54 to 1.35 respectively. With regard to defendant guilt, participants who were informed that the memories were recovered with hypnosis were almost 7 times less likely to 
render a guilty verdict $(p=.009$, odds ratio $=6.93$; control uninformed conditions $=56$ guilty vs. 28 innocent; hypnosis informed conditions = 38 guilty vs. 45 innocent). Psychological symptoms did not significantly predict defendant guilt nor did the symptom by hypnosis interaction. Neither hypnosis, psychological symptoms, nor the interaction were significant predictors of award of monetary damages with $p$-values ranging from .06 to .38 and odds ratios as indicated by the Wald coefficients ranging from .76 to 3.42 .

\section{Discussion}

The current study examined whether or not the use of hypnosis as a memory recovery technique had an effect on jurors' perceptions of plaintiff credibility, defendant guilt, and award of monetary damages given prior literature showing that people find hypnosis a credible memory recovery technique (Johnson \& Hauck, 1999; Poole, Lindsay, Memon, and Bull, 1995). Additionally, psychological symptoms indicative of child sexual abuse were included as a second variable to be studied. Overall, hypnosis appeared to effect jurors' perceptions of plaintiff credibility and defendant guilt, but not on award of monetary damages. On the other hand, psychological symptoms did not have an effect on jurors' perceptions of plaintiff credibility, defendant guilt, and award of monetary damages.

Contrary to expectations, people viewed hypnosis as being a less credible memory recovery technique than an uniformed technique and were less likely to render a guilty verdict when asked to make a dichotomous credible vs. not credible decision. One can infer from the data of this study that participants have prior knowledge of the concept of repressed memories from the media as indicated by their responses to the question "Are you familiar with the concept of repressed/recovered memories (meaning have you read or heard about these types of 
memories in the media or from another source)?" It is possible that participants have learned from the media that hypnosis is detrimental to memory recovery, as memory experts have been depicted in shows discussing the negative effects of hypnosis on memory accuracy. Across conditions, the findings show that participants viewed repressed memories with low credibility as indicated by mean responses of 4-5 on ratings of credibility and mean responses of approximately 5 on ratings of guilt. However given that the current study did not contain a continuous memory comparison group, it is unknown whether mock jurors in this study believed recovered memories less than continuous memories of child sexual abuse.

No significant results were found with regard to psychological symptoms, based on both the continuous and dichotomous dependent variable analyses. The lack of significant findings show that regardless of condition, the inclusion of psychological symptoms indicative of child sexual abuse had no effect on jurors' perceptions of plaintiff credibility, defendant guilt, and award of monetary damages. In contrast to previous findings that some clinicians believe that a variety of psychological symptoms indicated the presence of an abuse history, it can be inferred that people are reluctant to believe that these symptoms are indicative of child sexual abuse. This may be due to the fact that some of these symptoms, such as depression and anxiety, are common in the population and therefore may not be viewed as indicative of a trauma history.

Overall, participants were fairly lenient with their regard to award monetary damages to the prosecuting witness. Almost $50 \%$ of participants chose to award monetary damages to the prosecuting witness, regardless of the inclusion of psychological symptoms. This result is important to note due to the implications it raises for court cases. Specifically, participants awarded between $10 \%$ to $100 \%$ monetary damages to the prosecuting witness. In future cases, this outcome would be important to consider when any information is provided to 
the jury. Regardless of the different variables provided to jurors within a case, in this study jurors' perceived the plaintiff as someone who deserved to be awarded monetary damages at least $50 \%$ of the time.

Six caveats exist in terms of interpreting the results of this study. First, the hypnosis findings are contrary to a long line of research that was taken into account to formulate the hypnosis hypotheses. Therefore, replication of these results will be of paramount importance. Second, all questions assessing credibility, guilt, and monetary award within the survey were unable to be randomized due to Survey Monkey constraints. Third, three comprehension questions were included, while in reality only two could be used given a Survey Monkey response formatting issue. Therefore, with only two questions, it is possible that participants were included in the data set who did not fully comprehend the vignette. Fourth, there were differences in length between each of the vignettes used. Therefore, it is possible that the length of the vignette influenced results. However, differences in length resulted from careful experimental control which maintained consistency of particular baseline information in all of the vignettes but added and subtracted only the critical information needed for the experimental conditions. Fifth, the regression analyses may have been underpowered to detect an effect of psychological symptoms, although the analyses of variance also were non-significant and the $p$ values were not close to approaching significance. Finally, the current study investigated the effects of a female who had recovered memories. Future research should investigate whether the veracity of recovered memories differs for males. 
Table 1

Means and Standard Deviations of the Continuous Dependent Variable Results

\begin{tabular}{lc}
\hline Table 1. Continuous Dependent Variable Results & \\
\hline Dependent Variable by Condition & Mean (S.D.) \\
Plaintiff Credibility & $17.74(6.99)$ \\
Hypnosis: Informed/Symptoms: Informed & $18.63(5.64)$ \\
Hypnosis: Uninformed/Symptoms: Uninformed & \\
Hypnosis: Informed/Symptoms: Uniformed & $15.75(6.05)$ \\
Hypnosis: Uninformed/Symptoms: Informed & $19.05(5.83)$ \\
& \\
Defendant Guilt & $11.10(4.93)$ \\
Hypnosis: Informed/Symptoms: Informed & $11.25(5.13)$ \\
Hypnosis: Uninformed/Symptoms: Uninformed & \\
Hypnosis: Informed/Symptoms: Uninformed & $9.64(4.83)$ \\
Hypnosis: Uninformed/Symptoms: Informed & $12.59(4.85)$ \\
& \\
Likelihood to Award Monetary Damages to the & \\
Plaintiff & \\
Hypnosis: Informed/Symptoms: Informed & $54.87(36.41)$ \\
Hypnosis: Uninformed/Symptoms: Uninformed & $51.25(34.80)$ \\
Hypnosis: Informed/Symptoms: Uniformed & \\
Hypnosis: Uninformed/Symptoms: Informed & $46.82(36.14)$ \\
& $44.77(38.12)$ \\
\end{tabular}

Note: Scales differ across each dependent variable. For plaintiff credibility, the maximum score was 30 . For defendant guilt, the maximum score was 20 . For likelihood of awarding monetary damages, a Likert-type scale rating for percentage amount was used, in which the maximum score was 100 . 


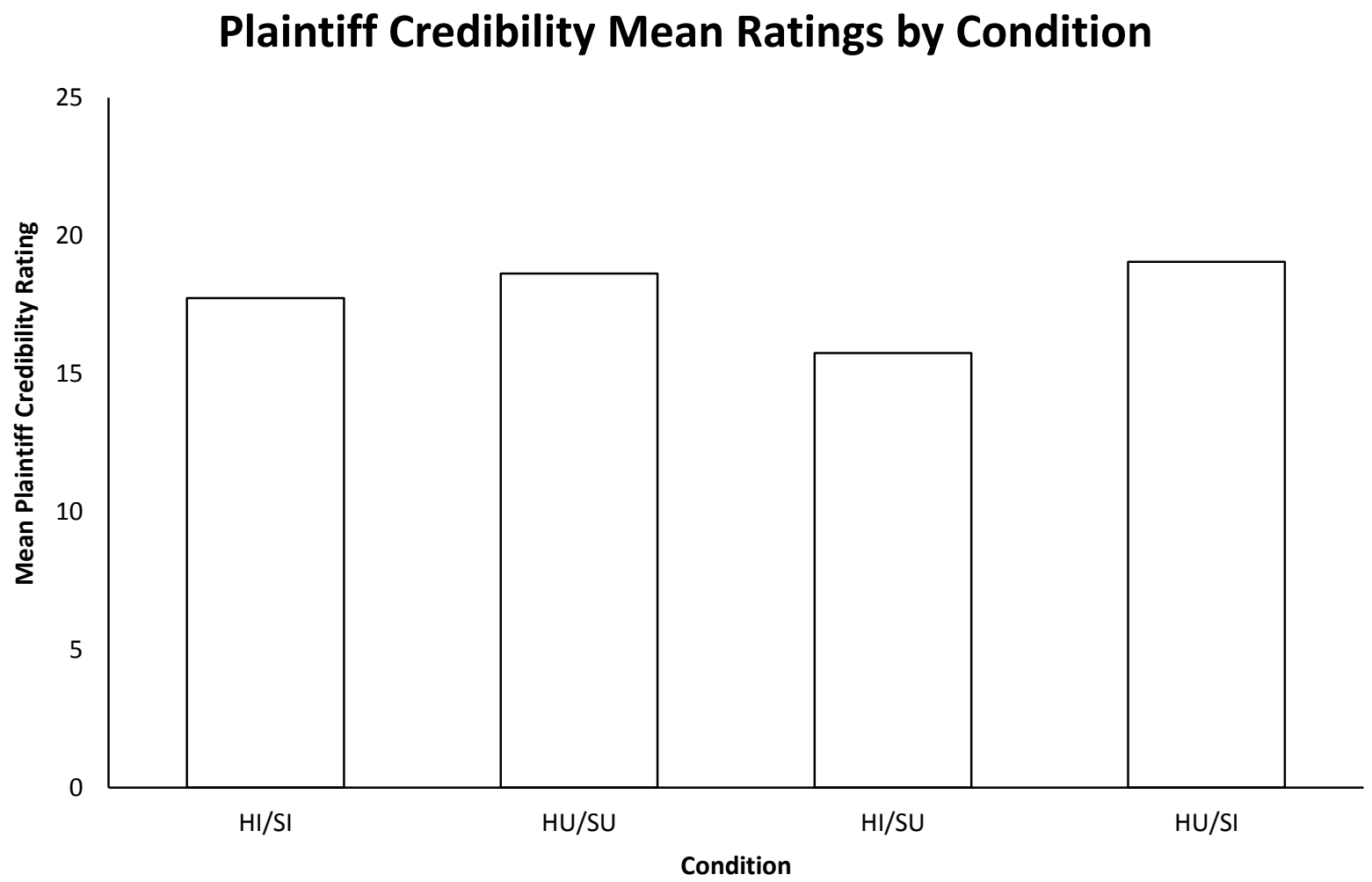

Figure 1. Mean ratings of plaintiff credibility by condition $(\mathrm{HI}=$ hypnosis informed, $\mathrm{SI}=$ psychological symptoms informed, $\mathrm{HU}=$ hypnosis uninformed, $\mathrm{SU}=$ psychological symptoms uninformed). The maximum total credibility score was 30. 


\section{Defendant Guilt Mean Ratings by Condition}

14

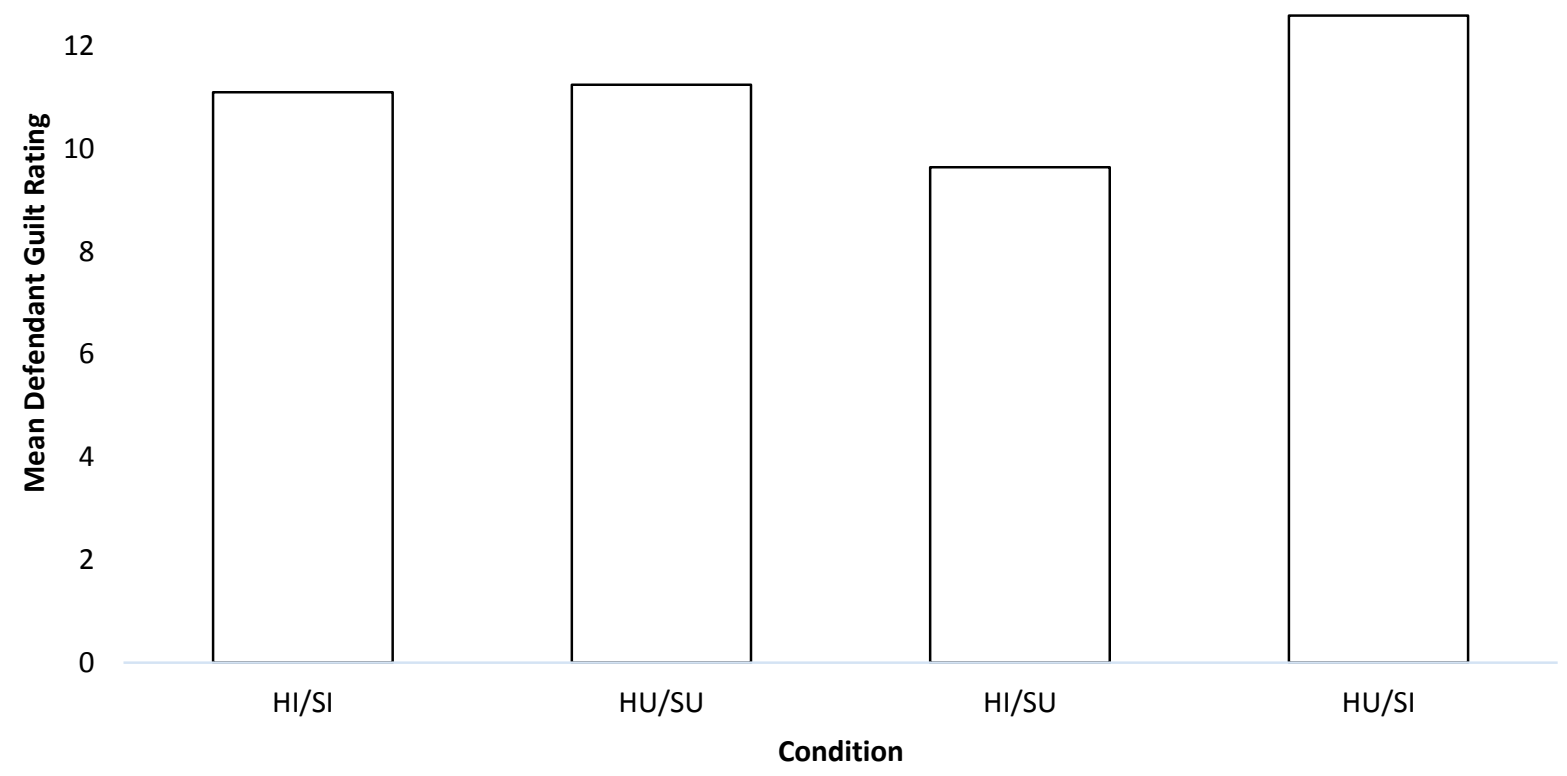

Figure 2. Mean ratings of defendant guilt by condition $(\mathrm{HI}=$ hypnosis informed, $\mathrm{SI}=$ psychological symptoms informed, HU = hypnosis uninformed, $\mathrm{SU}=$ psychological symptoms uninformed). The maximum total defendant guilt score was 20. 


\section{Award of Monetary Damages Mean Percentage Ratings by Condition}

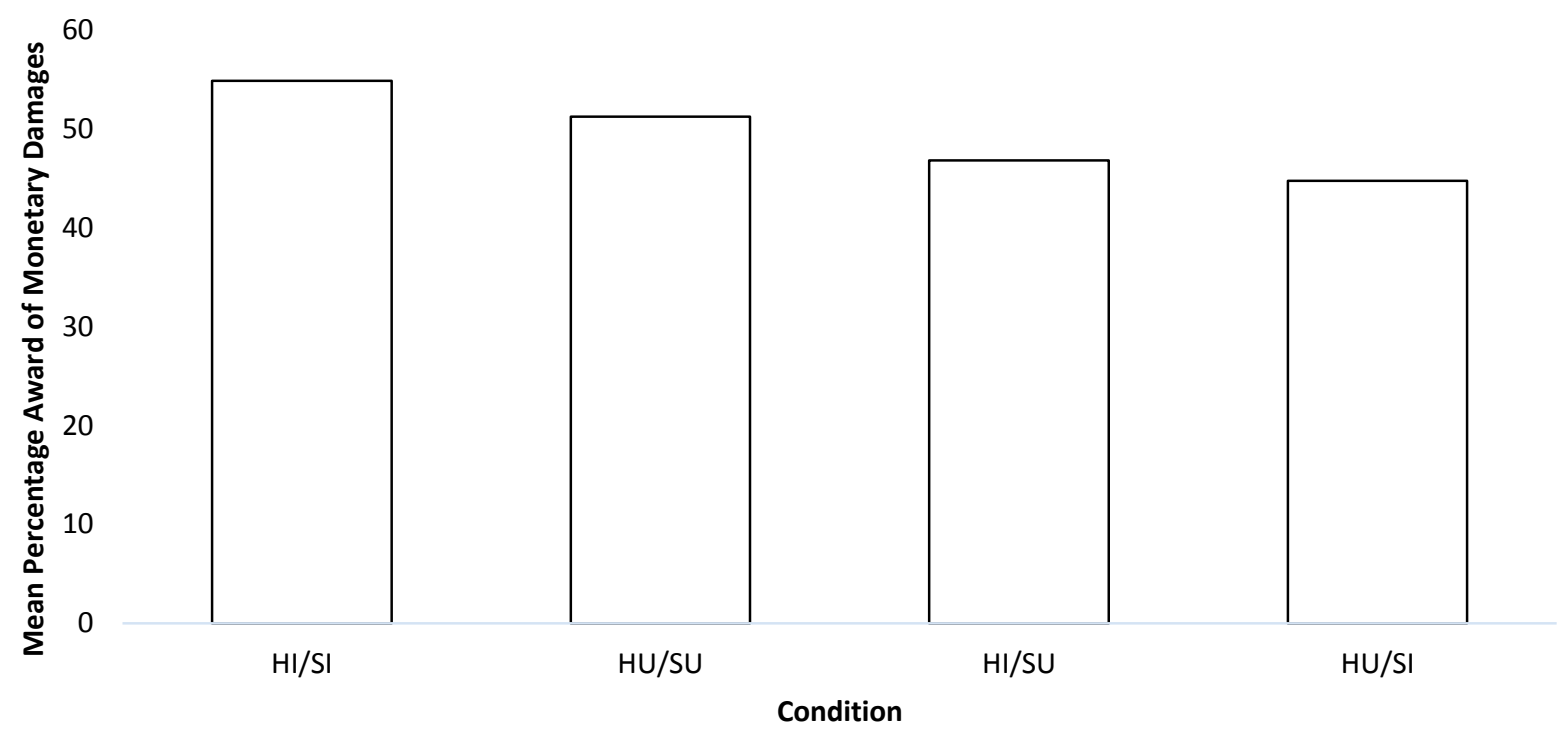

Figure 3. Mean ratings of percentage of award of monetary damages by condition ( $\mathrm{HI}=$ hypnosis informed, SI = psychological symptoms informed, $\mathrm{HU}=$ hypnosis uninformed, $\mathrm{SU}=$ psychological symptoms uninformed). A Likert-type scale rating for percentage amount was used, in which the maximum score was 100 . 


\section{References}

Banyard, V. L., Arnold, S., \& Smith, J. (2000). Childhood sexual abuse and dating experiences of undergraduate women. Child Maltreatment, 5(1), 39-48.

Bottoms, B. L. \& Goodman, G. S. (1994). Perceptions of children's credibility in sexual assault cases. Journal of Applied Social Psychology, 24(8), 702-732.

Brimacombe, E., Jung, S., Garrioch, L., \& Allison, M. (2003). Perceptions of older adult eyewitnesses: Will you believe me when I'm 64? Law and Human Behavior, 27(5), $507-$ 521.

Brimacombe. E., Quinton, N., Nance, N., \& Garrioch, L. (1997). Is age irrelevant? Perceptions of young and old adult eyewitnesses. Law and Human Behavior, 21(6), 619-633.

Chaffin, M., Silovsky, J. F., \& Vaughn, C. (2005). Temporal concordance of anxiety disorders and child sexual abuse: Implications for direct versus artifactual effects of sexual abuse. Journal of Clinical Child and Adolescent Psychology, 34(2), 210-222.

Claes, L. \& Vandereycken, W. (2007). Is there a link between traumatic experiences and selfinjurious behaviors in eating-disordered patients? Eating Disorders, 15, 305-315.

Coleman, B. L., Stevens, M. J., \& Reeder, G. D. (2001). What makes recovered-memory testimony compelling to jurors? Law and Human Behavior, 25(4), 317-337.

DelMonte, M. M. (2000). Retrieved memories of childhood sexual abuse. British Journal of Medical Psychology, 73, 1-13.

American Psychiatric Association. (2000). Diagnostic and statistical manual of mental disorders (4th ed., text revision). Washington DC: American Psychiatric Association. 
Farley, M. \& Keaney, J. C. (1997). Physical symptoms, somatization, and dissociation in women survivors of childhood sexual assault. Women \& Health, 25(3), 33-45.

Fox, S. G. \& Walters, H. A. (1986). The impact of general versus specific expert testimony and eyewitness confidence upon mock juror judgment. Law and Human Behavior, 10(3), 215-227.

Gal, G., Levav, I. \& Gross, R. (2011). Psychopathology among adults abused during childhood or adolescence: Results from the Israel-based world mental health survey. The Journal of Nervous and Mental Disease, 199(4), 222-229.

Golding, J. M., Sego, S. A., Sanchez, R. P., \& Hasemann, D. (1995). The believability of repressed memories. Law and Human Behavior, 19(6), 569-592.

Golding, J. M., Sanchez, R. P., Sego, S. A. (1996). Do you believe in repressed memories? Professional Psychology: Research and Practice, 27(5), 429-437.

Goodman-Delahunty, J., Cossins, A., \& O’Brien, K. (2010). Enhancing the credibility of complainants in child sexual assault trials: The effect of expert evidence and judicial directions. Behavioral Sciences and the Law, 28, 769-783.

Goodman, G. S., Batterman-Faunce, J. M., Schaaf, J. M., \& Kenney, R. (2002). Nearly 4 years after an event: Children's eyewitness memory and adults' perceptions of children's accuracy. Child Abuse \& Neglect, 26, 849-884.

Goodman, G. S., Golding, J. M, Helgeson, V. S., Haith, M. M., \& Michelli, J. (1987). When a child takes the stand: Jurors' perceptions of children's eyewitness testimony. Law and Human Behavior, 11(1), 27-39. 
Green, J. P., Lynn, S. J., \& Malinoksi, P. (1998). Hypnotic pseudomemories, prehypnotic warnings, and the malleability of suggested memories. Applied Cognitive Psychology, 12, 431-444.

Holcomb, M. J., Jacquin, K. M. (2007). Juror perceptions of child eyewitness testimony in a sexual abuse trial. Journal of Child Sexual Abuse, 16(2), 79-95.

Holliday, R. E., Brainerd, C. J., \& Reyna, V. F. (2011). Developmental reversals in false memories: Now you see them, now you don't! Developmental Psychology, 47(2), 442449.

Johnson, M. E. \& Hauck, C. (1999). Beliefs and opinions about hypnosis held by the general public: A systematic evaluation. American Journal of Clinical Hypnosis, 42(1), 10-20.

Kaplow, J. B., Hall, E., Koenen, K. C., Dodge, K. A., Amaya-Jackson, L. (2008). Dissociation predicts later attention problems in sexually abused children. Child Abuse \& Neglect, 32, 261-275.

Kisiel, C. L. \& Lyons, J. S. (2001). Dissociation as a mediator of psychopathology among sexually abused children and adolescents. American Journal of Psychiatry, 158(7), 10341039.

Krackow, E., \& Lynn, S. J. (2003). Is there touch in the game of twister? The effects of innocuous touch and suggestive questions on children's eyewitness memory. Law \& Human Behavior, 27, 589-604. 
Krackow, E. \& Lynn, S. J. (2010) Event report training: An examination of the efficacy of a new intervention to improve children's eyewitness reports. Applied Cognitive Psychology, 24, 868-884.

Krackow, E., Lynn, S. J., \& Payne, D. G. (2006). The death of Princess Diana: The effects of memory enhancement procedures on flashbulb memories. Imagination, Cognition and Personality, 25(3), 197-219.

Kugler, B. B., Bloom, M., Kaercher, L. B., Traux, T. V., \& Storch, E. A. (2012). Somatic symptoms in traumatized children and adolescents. Child Psychiatry and Human Development, 43, 661-673.

Loftus, E. F. (1993). The reality of repressed memories. American Psychologist, 48, 518-537.

Lynn, S. J., Fassler, O., \& Knox, J. (2005). Hypnosis and the altered state debate: Something more or nothing more? Contemporary Hypnosis, 22(1), 39-45.

Lynn, S. J. \& Kirsch, I. I. (1996). Alleged alien abductions: False memories, hypnosis, and fantasy proneness. Psychological Inquiry, 7(2), 151-155.

Lynn, S. J., Lock, T., Loftus, E. F., Krackow, E., \& Lilienfeld, S. O. (2014). Science and pseudoscience in clinical psychology. New York, NY, US: Guilford Press.

Lynn, S. J., Lock, T. G., Myers, B., \& Payne, D. G. (1997). Recalling the unrecallable: Should hypnosis be used to recover memories in psychotherapy? Current Directions in Psychological Science, 6(3), 79-83.

Lynn, S. J., Neuschatz, J., \& Fite, R. (2001). Hypnosis and memory: Implications for the courtroom and psychotherapy. Memory and Suggestibility in the Forensic Interview, 287. 
Lynn, S. J. \& O’Hagen, S. (2009). The sociocognitive and conditioning and inhibition theories of hypnosis. Contemporary Hypnosis, 26(2), 121-125.

Lynn, S. J. \& Pezzo, M. (1994). Close encounters of a third kind: Simulated hypnotic interviews of alien contacts. Paper presented at the meeting of the American Psychological Association, Los Angeles.

Lynn, S. J. \& Rhue, J. W. (1994). Dissociation: Clinical and theoretical theories. New York, NY, US: Guilford Press.

Malinoski, P. T. \& Lynn, S. J. (1999). The plasticity of early memory reports: Social pressure, hypnotizability, compliance and interrogative .suggestibility. International Journal of Clinical and Experimental Hypnosis, 47(4), 320-345.

Maniglio, R. (2010). Child sexual abuse in the etiology of depression: A systematic review of reviews. Depression and Anxiety, 27, 631-642.

Marmelstein, L. R. \& Lynn, S. J. (1999). Normative, group and hypnotic influences on early autobiographical memory reports. International Journal of Clinical and Experimental Hypnosis, 47(4), 301-319.

Mazzoni, G. A., Loftus, E. F., \& Kirsch, I. (2001). Changing beliefs about implausible autobiographical memories. Journal of Experimental Psychology: Applied, 7, 51-59.

McAuliff, B. D. \& Kovera, M. B. (2007). Estimating the effects of misleading information on witness accuracy: Can experts tell jurors something they don't already know? Applied, Cognitive Psychology, 21, 849-870. 
Messman-Moore, T. L. \& Garrigus, A. S. (2007). The association of child abuse and eating disorder symptomatology: The importance of multiple forms of abuse and revictimization. Journal of Aggression, Maltreatment \& Trauma, 14(3), 51-72.

Nachson, I., Read, J. D., Seelau, S. M., Goodyear-Smith, F., Lobb, B., Davies, G., Glicksohn, J., Lifschitz, M., \& Brimacombe, E. (2007). Effects of prior knowledge and expert statement on belief in recovered memories: An international perspective. International Journal of Law and Psychiatry, 30, 224-236.

Naka, M. \& Maki, Y. (2006). Belief and experience of memory recovery. Applied Cognitive Psychology, 20, 649-659.

Nash, M. R., Johnson, L. S., \& Tipton, R. D. (1979). Hypnotic age regression and the occurrence of transitional object relationships. Journal of Abnormal Psychology, 88(5), 547-555.

Ost, J., Wright, D. B., Easton, S., Hope, L., \& French, C. C. (2013). Recovered memories, satanic abuse, dissociative identity disorder and false memories in the UK: A survey of clinical psychologists and hypnotherapists. Psychology, Crime and Law, 19(1), 1-19.

Pezdek, K., Avila-Mora, E., \& Sperry, K. (2010). Does trial presentation medium matter in jury simulation research? Evaluating the effectiveness of eyewitness expert testimony. Applied, Cognitive Psychology, 24, 673-690.

Pezdek, K. \& Banks, W. (1996). The recovered memory/false memory debate. San Diego, CA, US: Academic Press. 
Poole, D. A., Lindsay, D. S., Memon, A., \& Bull, R. (1995). Psychotherapy and the recovery of memories of childhood sexual abuse: U.S. and British practioniers' opinions, practices, and experiences. Journal of Consulting and Clinical Psychology, 63(3), 426-437.

Rakow, A., Smith, D., Begle, A. M., \& Ayer, L. (2011). The association of maternal depressive symptoms with child externalizing problems: The role of maternal support following child sexual abuse. Journal of Child Sexual Abuse, 20, 467-480.

Rind, B., Tromovitch, P., \& Bauserman, R. (1998). A meta-analytic examination of assumed properties of child sexual abuse using college samples. Psychological Bulletin, 124(1), $22-53$.

Rotzien, A. L. (2002). Factors influencing juror verdict in a case involving repressed memories of abuse. Current Psychology, 21(3), 220-239.

Rumstein-McKean, O. \& Hunsley, J. (2001). Interpersonal and family functioning of female survivors of childhood sexual abuse. Clinical Psychology Review, 21(3), 471-490.

Tayloe, D. R. (1995). The validity of repressed memories and the accuracy of their recall through hypnosis: A case study from the courtroom. American Journal of Clinical Hypnosis, $37(3), 25-31$.

Tessier, P., \& Krackow, E. (2013). Jurors' perceptions of child witnesses: The effects of interviewing technique and research knowledge. Poster presented at the America Psychology-Law Society meeting, Portland. 
Thomas, R., DiLillo, D., Walsh, K., \& Polusny, M. A. (2011). Pathways from child sexual abuse to adult depression: The role of parental socialization of emotions and alexithymia. Psychology of Violence, 1(2), 121-135.

Turell, S. C. \& Armsworth, M. W. (2003). A log-linear analysis of variables associated with selfmutilation behaviors of women with histories of child sexual abuse. Violence Against Women, 9, 487-512.

Wheatcroft, J. M, Wagstaff, G. F., \& Kebbell, M. R. (2004). The influence of courtroom questioning style on actual and perceived eyewitness confidence and accuracy. Legal and Criminological Psychology, 9, 83-101.

Woody, W. D. \& Forrest, K. D. (2009). Effects of false-evidence ploys on expert testimony on jurors' verdicts, recommended sentences, and perceptions of confession evidence. Behavioral Sciences and the Law, 27, 333-360. 
Appendix 1

\section{Case Vignette Examples.}

\section{Vignette 1.}

Vignette describing no memory recovery technique and no psychological symptoms present.

An adult female recovered memories of child sexual abuse during a therapy session. She previously denied a history of sexual abuse. After therapy, she reported several incidences of abuse by her father when her mother was away on business trips. The alleged abuse occurred between the ages of 4 and 7. She was able to report vivid and detailed memories of these incidents. The woman is suing her father for mental health damages.

\section{Vignette 2.}

Vignette describing no memory recovery technique and psychological symptoms present.

An adult female recovered memories of child sexual abuse during a therapy session. She previously denied a history of sexual abuse. After therapy, she reported several incidences of abuse by her father when her mother was away on business trips. The alleged abuse occurred between the ages of 4 and 7. She was able to report vivid and detailed memories of these incidents. This person came to therapy because she had symptoms of depression and anxiety including, but not limited, to panic attacks, intermittent binge eating, and also reported reluctance to develop close relationships. The woman is suing her father for mental health damages.

\section{Vignette 3.}

Vignette describing hypnosis disclosed and psychological symptoms present.

An adult female recovered memories of child sexual abuse during a therapy session in which she received hypnosis. Prior to receiving hypnosis, she had previously denied a history of sexual abuse. After hypnosis, she reported several incidences of abuse by her father when her mother was away on business trips. The alleged abuse occurred between the ages of 4 and 7 . She was able to report vivid and detailed memories of these incidents. This person came to therapy because she had symptoms of depression and anxiety including, but not limited to, panic attacks, intermittent binge eating, and also reported reluctance to develop close relationships. The woman is suing her father for mental health damages. 
Appendix 1

\section{Vignette 4.}

Vignette describing hypnosis disclosed and no psychological symptoms present.

An adult female recovered memories of child sexual abuse during a therapy session in which she received hypnosis. Prior to receiving hypnosis, she had previously denied a history of sexual abuse. After hypnosis, she reported several incidences of abuse by her father when her mother was away on business trips. The alleged abuse occurred between the ages of 4 and 7 . She was able to report vivid and detailed memories of these incidents. The woman is suing her father for mental health damages. 